\title{
The Effects Of Violent Events On The Mexican Stock Market
}

\author{
Magali Valero, University of Michigan Dearborn, USA \\ Jorge Valero-Gil, Universidad Autónoma de Nuevo León, Mexico
}

\begin{abstract}
We study the impact of violent events on the Mexican stock market, by using an event study approach. Our results show that the Mexican stock market reacts negatively to news of violent events. This news, however, have no spillover effects into other Latin American and emerging markets, nor to the U.S. market, where their occurrence was inconsequential.
\end{abstract}

Keywords: Violence; Financial Markets; Event Study; Mexico

\section{INTRODUCTION}

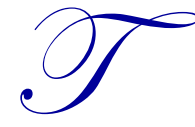

his paper studies the impact of violent events on the Mexican stock market. Mexico experienced a strong increase in violence, including homicide rates, starting in 2007, after a relatively stable period. The spike followed the election of President Felipe Calderón, and his increased emphasis on fighting drug cartels in Mexico. There has been growing interest on how this increased violence affects Mexico. There is scant research on the economic impact of this increased violence in Mexico. For instance, Enamorado, Lopez-Calva \& Rodriguez-Castelan (2014) show, using the case of Mexico, that crimes related to drugs deter economic growth. Further, Robles, Calderón \& Magaloni (2013) find that increased violence in Mexico reduces labor force participation and decreases the proportion of people who own a business. We add to this literature by studying the effect of violent events during the 1993 to 2012 period on the financial market.

Our paper partly relates to the literature on terrorist attacks. A large number of terrorist attacks occur in Latin America (Karolyi, 2006). A strand of literature focuses on how terror attacks have influenced the stock market. Findings indicate negative price reactions on the stock market following a terrorist attack (Chen \& Siems, 2004; Karolyi \& Martell, 2010; Brounrn \& Derwall, 2010; Chesney, Reshetar \& Karaman, 2011). Increased violence could also lead to a fall in the stock market, as these events can also affect investors' perceptions about value and hence influence stock prices. We further this literature by examining the impact of violent events in the stock market.

Our paper contributes to the literature in that we look at how violent events can impact the stock market, in a country with no perceived terrorism. Even though no terrorism plagues Mexico, it is a country that has experienced many violent events. The cases we consider are not terrorism per se, but violent events that could or not be related with Mexico's war on drugs. We question if these criminal activities have an immediate impact on the stock market in Mexico, as well as on other markets. We also use an innovative way to identify important violent events. Rather than using crime or homicide indexes, we look at international newspapers for news of violence in Mexico, and select events that appeared in at least two such newspapers. The events we select are thus those that received international publicity, and thus are not minor local events.

We identify 18 violent events in Mexico that were reported in at least two international newspapers, and use event study methodology to measure how the Mexican stock market reacted to the news of such events. We also look at the stock market in the United States as well as other Latin American countries to measure any spillover effects of the violent events in Mexico to other markets. We find that some violent events do impact the stock market in Mexico. Overall, our findings suggest a $1.10 \%$ negative cumulative average abnormal return over the 3 -day period surrounding the violent event, which is statistically significant at the $5 \%$ level. We also find the United States stock market and 
stock markets of emerging markets in general are not affected by the violent event, suggesting no panic spillovers to other countries. Therefore, the effect of violence on the stock market seems to be a local event.

This paper is organized as follows. In Section 2, we review the literature related to violence in Mexico and to the effect on financial markets of terrorist attacks; and in Section 3, we present the hypothesis of the study. Section 4 discusses how the sample was formed and the event study methodology we follow to measure abnormal returns. Section 5 then presents our empirical results, for both the Mexican stock market and other capital markets. In Section 6, we conclude.

\section{LITERATURE REVIEW}

Our paper fits in the intersection of two different strands of literature: on the one hand, the effects of violence on the financial economy in general and the stock market in particular; on the other, the effects that the increased violence in Mexico has had on the country.

Violent events have been shown to alter financial markets, the literature on terrorism finds terrorism alters economic behavior and it can affect stock prices. In general, previous studies find a negative transitory effect on the stock market upon a terrorist attack, but the magnitudes vary among countries. For instance, Aslam and Kang (2015) use event study methodology to show a short-lived negative impact of terrorist attacks on the Pakistani stock market, with the market recovering in one day. The negative impact depends on the severity of the terrorist attack, with more severe attacks related to more negative abnormal returns. Cross-country studies also find evidence of negative abnormal returns to terrorist attacks, which are for the most part transitory, and with some markets recovering faster than others do. Chen and Siems (2004) find negative abnormal returns of terrorist attacks on global capital markets, with the U.S. market recovering faster compared to other global capital markets. Their findings also indicate that U.S. markets are more resilient than in the past. Kollias et al. (2011) use event study methodology to measure the impact of the Spain and London attacks of 2004 and 2005, finding a negative equity market impact. Although the effect is transitory, the London market seems to rebound much quicker than the Spanish market. In the study by Karolyi and Martell (2010), the focus is on firm specific terrorist attacks. Using a sample of 75 attacks their event study finds a negative stock price impact for affected firms on the day of the attack, which does not spillover to other firms and which is stronger in wealthier and more democratic countries. They also show human losses have a stronger negative impact compared to physical firm losses.

Comparing terrorist attacks with other disasters, Brounrn and Derwall (2010) find negative abnormal returns from terrorism are mild, but stronger than for earthquakes. They also find evidence of the impact being for local markets and industries directly affected by the attack. Beyond equity markets, terrorism can also have consequences on other financial markets. Chesney et al. (2011) capture the impact of attacks on a broad group of markets, including equity, bond and commodities, and use several different methodologies. They also find a negative impact of terrorism that is transitory. More recently, Goel, Cagle \& Shawky (2017) study large-scale terrorist attacks both inside and outside the United States. Using event study methodology, they find no significant effect of terrorist attacks on bond or stock market returns, with the exception of the September 11, 2001 terrorist attacks.

Although overall there seems to be a negative impact on firms from terrorism, not all industries suffer from the terrorist attacks. Apergis and Apergis (2016) show that the defense industry benefited from the 2015 terrorist attacks in Paris, as their event study finds a positive effect on the returns of companies in the defense industry. As terrorism affects investment returns, it can also lead to a change in risk behavior. Wang and Young (2020) study mutual fund flows and find investor risk aversion falls with an increase in terrorist activity in the case of the United States. In the month following a terrorist attack, investors reduce their holdings of equity funds and increase their holdings of bond funds, a decrease in risk appetite.

Terrorism and violence can also affect businesses in real ways. One possibility is that terrorism changes the risks that businesses face. For example, Dai, Rau, Stouraitis \& Tan (2020) find terrorism risk increases CEO pay in the United States, and compensation structure changes with terrorist attacks, with more preference towards a cash compensation for CEOs of firms in proximity of the attacks. Terrorism can also affect firm performance. Tingbani, Okafor, Tauringana \& Zalata (2019) study the relation between terrorism and business failures in a cross-country study and 
found an increase in terrorism decreases business failure in the case of developing countries but not in developed economies.

The distinction between developed and developing economies is important. The level of socio-economic development matters for terrorism, with terrorism being more attractive in countries with poor socio-economic conditions (Freytag et al. 2011). Additionally, terrorism also affects the economy, as it can reduce investment and consumption (Eckstein \& Tsiddon, 2004; Llussá \& Tavares, 2011). The developing economy of Mexico has gone through periods of increased violence in the country. The period we study is one where an increase in violence was experienced within Mexico. In particular, we include the period of time after President Felipe Calderón declared the war on drugs, at which time the homicide rate increased in Mexico (Bel \& Holst, 2018; Balmori de la Miyar, 2016). This increase in violence in the country has had several effects.

Enamorado et al. (2014) study the effect of crime on growth, and find that in the case of Mexico, drug-related crime deters growth, but non-drug related crime does not. The increase in violence in Mexico led to lower GDP per capita of the states, with more violence related to a stronger shift in GDP per capita (Bel \& Holst, 2018). Balmori de la Miyar (2016) shows that it was a reduction in per capita consumption and a reduction in productive investment, especially for the states that had military operations, which led to the fall in GDP. At the household level, the increased violence also had significant effects. Increased violence has been associated with increased inequality, as more homicides happen in municipalities that have higher income inequality (Enamorado, Lopez-Calva, Rodriguez-Castelan \& Winkler, 2016). This inequality effect is especially strong during the periods of the Mexican drug war. The increased violence has also impacted the country's youth. Young people exposed to violence faced financial hardship that resulted in less educational attainment for them. Additionally, youth were more likely to be employed if there was a high level of violence in their municipality (Brown \& Velazquez, 2017). Velazquez (2020) looks at the effect of the drug related violence in Mexico on labor market outcomes. She finds that the violent environment at the municipality level leads to a fall in earnings and productivity of males, as well as to self-employed women exiting the labor force.

Although the effects of violence on the Mexican economy have been studied at the macroeconomic and microeconomic levels, little work has been done to understand the impact of such violence on businesses and the financial market. An exception to this is Robles et al. (2013) who study the impact of the drug war on businesses and find a significant lack of growth among businesses during this period. In particular, Robles et al. (2013) find that municipalities with increased drug violence experienced a fall in electricity consumption and hence in economic activity. Increased violence leads to a decrease in the proportion of people who own a business, perhaps because such businesses move somewhere else. The impact of the increased violence on businesses could also affect companies listed on stock exchanges, and hence our focus is on the impact of violent events on the Mexican stock market.

\section{RESEARCH HYPOTHESIS}

A violent event can have many different economic consequences related to growth, employment, tourism, etc. In addition, it can increase risk and therefore affect investments, and also affect firms expected profits and hence firm value, influencing the stock market. In particular, violent events can lead to increases in investors' risk aversion, as well as increases in consumers' risk aversion and hence a reduction in consumption. If the persistence of violent events increases risk aversion by firms, this could cause a reduction in the investment activities of such firms. Nasir, Rockmore and Tan (2020) show that the increase in violence in Mexico increased risk aversion significantly. Further, the persistence of violent events in a country can increase the costs of doing business, as companies increase their expenditures on security, which can also affect investor's perceptions about firm value. Since stock prices reflect the expectations about the future, as new information is received stock prices might react to this news. Violence can change risk aversion and increase the costs of doing business, so investors re-assess their perceptions about value, affecting the stock value of firms. In our framework, as information about a violent event reaches the market investors might flee and turn to safer alternatives, which can lead to a fall in stock prices. As a violent event unfolds, investors re-evaluate the firms' and their ability to weather the changes that might arise by such event, thus updating their expectations about firm value. Thus, the following hypothesis follows:

H1: Violent events in Mexico are associated with negative abnormal returns in the Mexican Stock market. 
One would expect the effects of the increased violence to be local. Risk aversion, investment activities, increased costs of doing business, and perceptions about firm value should affect local companies and thus the local market. The following then follows:

H2: The effect on the stock market is local and does not affect other international markets.

\section{DATA AND METHODOLOGY}

Since there were many violent events during our period of study, we select violent events that had international dissemination as our focus. We search in LexisNexis Academic for all news of violence in Mexico, by using the search terms "Violence" and "Mexico", within three major newspapers: the Financial Times, the New York Times, and the Wall Street Journal. The search produces a total of 936 news articles, of which 264 appeared in the Wall Street Journal, 159 in Financial Times, and 513 in the New York Times. We then read these articles to identify cases where the news appears in more than one newspaper. We find 75 cases that appear in more than one newspaper, and among these, we select the cases where the news refers to the announcement of a violent event ${ }^{1}$. Our final sample includes 18 violent events that occurred between 1993 and 2012, where the news of the event reached at least two of the three international newspapers considered.

The focus on multiple violent events rather than focusing on only one, for instance when the leading candidate to governor of the state of Tamaulipas was assassinated in 2010, provides a broader perspective as to the risks that firms and investors bear when facing the possibility of violent events. However, it is possible that some of these events are small and so we find no stock market effects of them happening.

In order to identify abnormal returns associated with our specific events, we employ standard event-study methodology. The event study methodology allows us to attribute abnormal returns to specific events. It is based on the efficient market hypothesis (Fama, Fisher, Jensen \& Roll, 1969), which posits that current prices reflect all available information, but they react as new information becomes available in the market. Event study methodology has been used in the literature to evaluate the impact on stock prices of various events, including terrorist events (Chen \& Siems, 2004; Abadie \& Gardeazabal, 2003).

Using daily data on a financial market index from DataStream, we find the logarithmic daily percentage index returns through:

$R_{i, t}=L N\left(P_{i, t} / P_{i, t-1}\right)$

Where $R_{i, t}$ refers to the return on index i for period $\mathrm{t}$, and $P_{i, t}$ is the price of the index at the end of period $\mathrm{t}$.

To measure abnormal returns, we follow the methodology described by Brown and Warner (1985) since we examine stock market indexes. We therefore test the significance of the impact of the event on the market by calculating the deviation of returns from its average. To measure these excess returns we utilize the mean-adjusted-returns approach; daily abnormal returns are estimated as:

$A R_{i, t}=R_{i, t}-\bar{R}_{i}$

$\bar{R}_{i}=\frac{1}{90} \sum_{t=-100}^{t=-11} R_{i, t}$

Where $A R_{i, t}$ is the abnormal return of stock index $\mathrm{i}$ on day $\mathrm{t}$, and $R_{i, t}$ is the realized return on stock index $\mathrm{i}$ on day $\mathrm{t}$. Abnormal returns are estimated as the deviation of realized return from its average during the estimation window,

\footnotetext{
${ }^{1}$ Some of the events captured are actually good news, for instance, if a drug lord is captured, or an arrest of someone in connection to a violent event; these are excluded from our analysis. We also exclude news that talk about violence in Mexico in general, by itself or in the context of some other event, examples would be the Pope's visit to Mexico and Presidential elections.
} 
days -100 to -11 , where day 0 refers to the day the event occurred. In cases where the market was closed at the time of the event (weekends or if the event was late in the afternoon) then the event day is defined as the next trading day to capture the effect.

The information about a violent event should be incorporated into stock prices instantaneously in an efficient market. However, our stock market data is measured at 3:00pm when the market closes. Since the violent event can occur at any time the prices can adjust to such event either on the same day or after, depending on the timing of such event. For instance, the impact of an event that occurs on Saturday, when the market is closed, will be reflected in the market once the market resumes on Monday, so we capture it by studying the change from Friday to Monday. Therefore, in addition to studying the abnormal return on the day of the event (day 0), we also look at three other windows surrounding the event. Although every effort was made to pinpoint the day and time of the event, we use a window of one day before to one day after the event day $(-1,+1)$ to make sure we capture the full effect of the event, as it is possible that the event occurred on a particular day but that the news did not affect the stock market until the following day. Further, it is also possible that the market learned about the event before the event was recorded. The two other event windows we use, $(-1,+5)$ and $(-1,+10)$, are used to gauge how long the effect lasted. For the event windows longer than one day we compute cumulative abnormal returns as:

$C A R_{i}=\sum_{t=t 1}^{t 2} A R_{i, t}$

Where $\mathrm{t} 1$ and $\mathrm{t} 2$ refer to the start and end days of the event window. Further, cumulative average abnormal returns are computed as:

$C A A R=\frac{1}{N} \sum_{i=1}^{N} C A R_{i}$

We use test statistics from Brown and Warner (1985) to denote significance of abnormal returns.

\section{EMPIRICAL RESULTS}

\subsection{Impact of Violent Events in the Mexican Stock Market}

The events that we identify are shown in Table 1, along with the source newspaper where the news appeared among the newspapers considered. Our sample selection includes events between the years of 1993 to 2012. Most of the events that we identify were in the post 2007 era, after the spike in violence in Mexico. The events appeared in at least two newspapers, with 7 events appearing in all three newspapers. 
Table 1. Sample Selection

\begin{tabular}{|c|c|c|c|}
\hline $\begin{array}{c}\text { Event } \\
\text { Number }\end{array}$ & Event Description & Event date & $\begin{array}{l}\text { News outlets where it } \\
\text { appeared }\end{array}$ \\
\hline 1 & Cardinal killed in shooting & 24 May 93 & FT, NYT \\
\hline 2 & Uprising in Chiapas & 1 January 1994 & FT, WSJ \\
\hline 3 & Colosio Assassinated & 23 March 1994 & FT, NYT, WSJ \\
\hline 4 & Jose Ruiz Massieu Assassinated & 28 September 1994 & FT, NYT, WSJ \\
\hline 5 & Rebels attack leaving 13 dead & 28 August 1996 & FT, NYT \\
\hline 6 & 45 dead in massacre & 22 December 1997 & FT, NYT, WSJ \\
\hline 7 & Top police official killed & 08 May 08 & WSJ, NYT \\
\hline 8 & 12 federal agents killed in Michoacán & 13 July 2009 & WSJ, NYT \\
\hline 9 & Killing of 17 students in Juarez & 31 January 2010 & WSJ, NYT \\
\hline 10 & $\begin{array}{l}\text { Killing of USA consulate worker and her husband in } \\
\text { Ciudad Juarez }\end{array}$ & 13 March 2010 & WSJ, NYT \\
\hline 11 & Kidnapping of Diego Fernandez de Ceballos & 14 May 2010 & WSJ, NYT \\
\hline 12 & Candidate to Governor assassinated & 28 June 2010 & FT, NYT, WSJ \\
\hline 13 & 18 Dead in Torreon Coahuila & 18 July2010 & WSJ, NYT \\
\hline 14 & 72 Migrants found dead in ranch & 24 August 2010 & FT, NYT, WSJ \\
\hline 15 & 2 American agents shot in Mexico & 15 February 2011 & FT, NYT, WSJ \\
\hline 16 & Arson kills 40 at Casino Royale & 26 August 2011 & FT, NYT, WSJ \\
\hline 17 & 25 Killed in social justice claim & 20 September 2011 & WSJ, NYT \\
\hline 18 & 49 bodies found by highway in Mexico & 13 May 2012 & FT, NYT \\
\hline
\end{tabular}

FT- Financial Times

NYT - New York Times

WSJ - Wall Street Journal

Table 2 shows the event day abnormal returns of the 18 events in our sample, as well as the cumulative abnormal returns for event windows $(-1,+1),(-1,+5)$, and $(-1,+10)$. We use the DataStream total market index for Mexico as our market index. In 14 out of the 18 events studied, negative abnormal returns on the event day $t=0$ was experienced. The four events with positive abnormal returns are not statistically significant. Further, four events have statistically significant abnormal returns on the event day, and those abnormal returns are negative. We can say that for these four events, we find a negative stock market reaction to the violent event. 
Table 2. Cumulative Average Abnormal Return by Event

\begin{tabular}{|c|c|c|c|c|}
\hline Event Number & Event-day AR(0) & CAR(-1, +1) & $\operatorname{CAR}(-1,+5)$ & $\operatorname{CAR}(-1,+10)$ \\
\hline \multirow{2}{*}{ 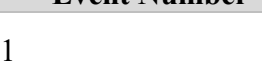 } & $0.14 \%$ & $-0.27 \%$ & $-0.54 \%$ & $-1.43 \%$ \\
\hline & $(0.12)$ & $(-0.13)$ & $(-0.17)$ & $(-0.35)$ \\
\hline \multirow{2}{*}{2} & $-3.69 \%$ & $-2.56 \%$ & $-7.05 \% * *$ & $-6.76 \%{ }^{*}$ \\
\hline & $(-3.35)$ & $(-1.34)$ & $(-2.42)$ & $(-1.77)$ \\
\hline \multirow{2}{*}{3} & $0.70 \%$ & $4.65 \%^{*}$ & $-1.42 \%$ & $-8.02 \%$ \\
\hline & $(0.47)$ & $(1.80)$ & $(-0.36)$ & $(-1.55)$ \\
\hline \multirow{2}{*}{4} & $-1.98 \% *$ & $-4.41 \%{ }^{* *}$ & $-7.28 \% * *$ & $-5.20 \%$ \\
\hline & $(-1.72)$ & $(-2.21)$ & $(-2.39)$ & $(-1.31)$ \\
\hline \multirow{2}{*}{5} & $-0.50 \%$ & $-0.82 \%$ & $-1.37 \%$ & $-2.27 \%$ \\
\hline & $(-0.53)$ & $(-0.50)$ & $(-0.55)$ & $(-0.69)$ \\
\hline \multirow{2}{*}{6} & $-0.09 \%$ & $-2.14 \%$ & $0.87 \%$ & $1.94 \%$ \\
\hline & $(-0.05)$ & $(-0.66)$ & $(0.18)$ & $(0.30)$ \\
\hline \multirow{2}{*}{7} & $-0.05 \%$ & $-1.70 \%$ & $0.35 \%$ & $-1.06 \%$ \\
\hline & $(-0.03)$ & $(-0.68)$ & $(0.09)$ & $(-0.21)$ \\
\hline \multirow{2}{*}{8} & $0.83 \%$ & $1.68 \%$ & $7.07 \%$ & $7.39 \%$ \\
\hline & $(0.48)$ & $(0.56)$ & $(1.54)$ & $(1.23)$ \\
\hline \multirow{2}{*}{9} & $-0.11 \%$ & $0.01 \%$ & $-1.24 \%$ & $-0.81 \%$ \\
\hline & $(-0.11)$ & $(0.01)$ & $(-0.48)$ & $(-0.24)$ \\
\hline \multirow{2}{*}{10} & $-0.05 \%$ & $0.16 \%$ & $1.00 \%$ & $1.42 \%$ \\
\hline & $(-0.05)$ & $(0.10)$ & $(0.40)$ & $(0.43)$ \\
\hline \multirow{2}{*}{11} & $-0.67 \%$ & $-3.49 \%^{* * *}$ & $-4.60 \%{ }^{* *}$ & $-1.83 \%$ \\
\hline & $(-0.91)$ & $(-2.72)$ & $(-2.35)$ & $(-0.71)$ \\
\hline \multirow{2}{*}{12} & $-0.31 \%$ & $-2.54 \%^{*}$ & $-3.12 \%$ & $-1.75 \%$ \\
\hline & $(-0.36)$ & $(-1.73)$ & $(-1.39)$ & $(-0.59)$ \\
\hline \multirow{2}{*}{13} & $0.16 \%$ & $-0.99 \%$ & $1.48 \%$ & $0.87 \%$ \\
\hline & $(0.18)$ & $(-0.63)$ & $(0.61)$ & $(0.28)$ \\
\hline \multirow{2}{*}{14} & $-1.90 \% *$ & $-1.95 \%$ & $-1.12 \%$ & $0.98 \%$ \\
\hline & $(-1.98)$ & $(-1.17)$ & $(-0.44)$ & $(0.29)$ \\
\hline \multirow{2}{*}{15} & $-0.15 \%$ & $-0.39 \%$ & $-1.22 \%$ & $-1.92 \%$ \\
\hline & $(-0.28)$ & $(-0.42)$ & $(-0.87)$ & $(-1.05)$ \\
\hline \multirow{2}{*}{16} & $0.37 \%$ & $1.02 \%$ & $2.45 \%$ & $-0.30 \%$ \\
\hline & $(0.36)$ & $(0.58)$ & $(0.91)$ & $(-0.08)$ \\
\hline \multirow{2}{*}{17} & $-1.98 \%{ }^{*}$ & $-2.85 \%$ & $-3.22 \%$ & $-5.07 \%$ \\
\hline & $(-1.68)$ & $(-1.39)$ & $(-1.03)$ & $(-1.24)$ \\
\hline \multirow{2}{*}{18} & $-1.05 \%$ & $-3.17 \%^{* * *}$ & $-3.75 \% * *$ & $-4.00 \% *$ \\
\hline & $(-1.78)$ & $(-3.10)$ & $(-2.40)$ & $(-1.96)$ \\
\hline
\end{tabular}

$\mathrm{t}$-statistics associated with the abnormal returns are in parenthesis

*Statistically significant at the .10 level; **Statistically significant at the .05 level; ***Statistically significant at the .01 level

We look at longer event windows to capture the full impact on the stock market of the event. Of the 18 events that we study, 13 experienced negative CARs during the $(-1,+1)$ window, 12 during the $(-1,+5)$ window and 13 in the $(-1$, +10 ) window surrounding the event. For two of our events, the uprising in Chiapas in 1994 and when 49 bodies were found by a highway in 2012 , the new information continued its negative effect on stock prices, as the $(-1,+10)$ CARs are still negative and statistically significant. 
Table 3. Cumulative Average Abnormal Returns over Event Windows

\begin{tabular}{|c|c|c|c|c|}
\hline Relative Days & $(0,0)$ & $(-1,+1)$ & $(-1,+5)$ & $(-1,+10)$ \\
\hline Mean CAR & $-0.58 \%$ & $-1.10 \%$ & $-1.27 \%$ & $-1.55 \%$ \\
\hline$\%$ Positive & $27.78 \%$ & $27.78 \%$ & $33.33 \%$ & $27.78 \%$ \\
\hline t-statistic & $-2.13^{* *}$ & $-2.16^{* *}$ & -1.57 & $-1.84^{*}$ \\
\hline
\end{tabular}

$\mathrm{t}$-statistics associated with the average cumulative abnormal returns

*Statistically significant at the .10 level; **Statistically significant at the .05 level; ***Statistically significant at the .01 level

Table 3 presents the cumulative average abnormal returns over the event windows. The average abnormal returns are negative and statistically significant for our events. The CAARs surrounding the event window, $(0,0)$ and $(-1,+1)$ are significant at the $5 \%$ level. The finding suggests a negative stock price impact of violent events in Mexico. We find a $-1.10 \%$ CAAR over the $(-1,+1)$ window, a negative impact on stock prices surrounding the violent event occurrence.

The results also show decreasing CAARs as the event window is allowed to increase, which implies a fall in the stock market index that continues over the period studied.

Figure 1. Cumulative Average Abnormal Returns by Relative Event Day

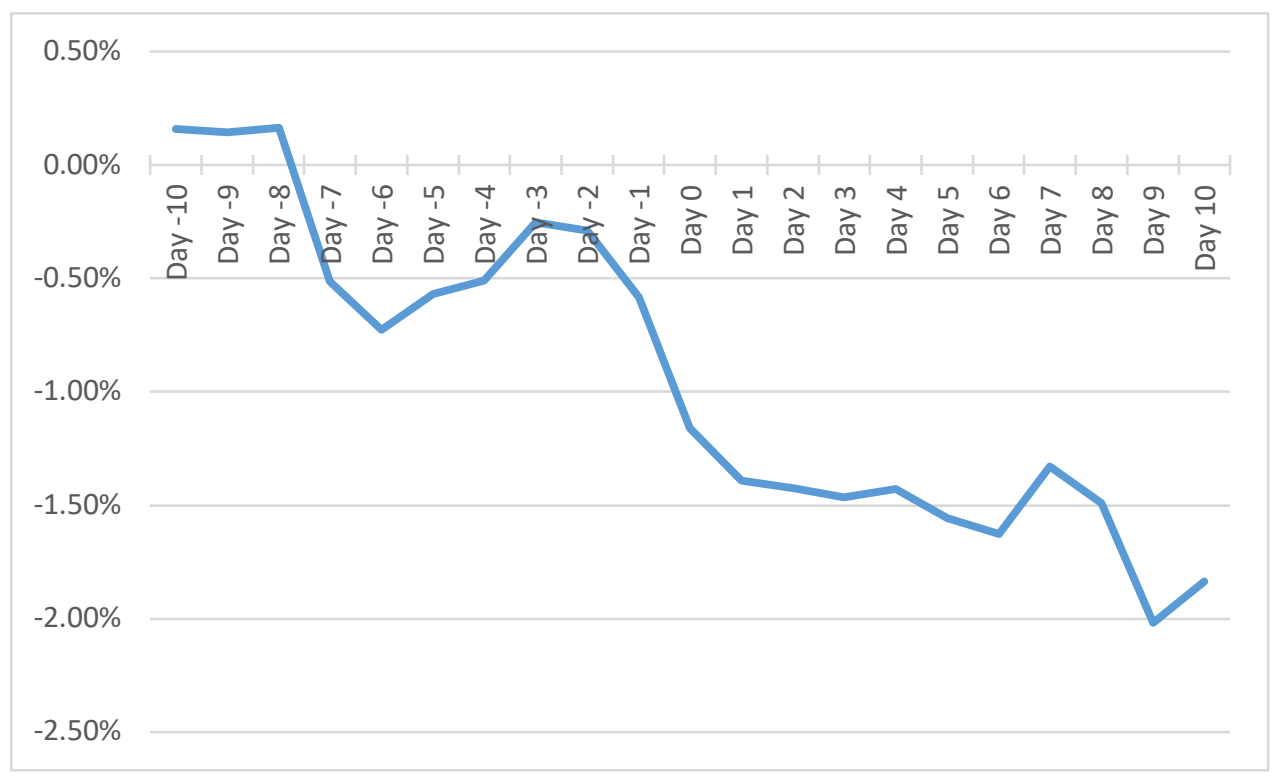

Figure 1 shows the cumulative average abnormal returns from 10 days before to 10 days after the event date. There is a strong drop in cumulative average returns at the onset of the event. The cumulative AAR is still negative 10 days posterior to the event. Overall, the results here support that there is a negative impact of violent events in the stock market in Mexico (H1).

\subsection{Impact of Violent Events in Mexico on other Capital Markets}

We now consider the possibility that other markets also react to violent events in Mexico. Spillover effects are possible as markets are interlinked. We use three other indexes taken from DataStream to measure the effect in other markets. Emerging Markets is an index containing stocks of emerging markets; Latin America is an emerging market index that only includes Latin American economies; and the U.S. market index, United States. We compare them against the index in the Mexican stock market, using the DataStream total market index for Mexico calculated in U.S. dollars for consistency with the other indexes. 
Table 4. CAAR over Event Window for Other Markets

\begin{tabular}{|c|c|c|c|c|}
\hline Relative Days & $(0,0)$ & $(-1,+1)$ & $(-1,+5)$ & $(-1,+10)$ \\
\hline \multicolumn{5}{|l|}{ Emerging Markets } \\
\hline Mean CAR & $-0.39 \%$ & $-0.80 \%$ & $-1.16 \%$ & $-0.88 \%$ \\
\hline$\%$ Positive & $38.89 \%$ & $38.89 \%$ & $50.00 \%$ & $55.56 \%$ \\
\hline t-statistic & -1.56 & -1.57 & -1.11 & -0.70 \\
\hline \multicolumn{5}{|l|}{ Latin America } \\
\hline Mean CAR & $-0.29 \%$ & $-1.09 \%$ & $-0.98 \%$ & $-0.25 \%$ \\
\hline$\%$ Positive & $44.44 \%$ & $44.44 \%$ & $50.00 \%$ & $55.56 \%$ \\
\hline t-statistic & -0.99 & -1.53 & -0.82 & -0.17 \\
\hline \multicolumn{5}{|l|}{ United States } \\
\hline Mean CAR & $0.20 \%$ & $-0.62 \%$ & $-1.20 \%$ & $-0.53 \%$ \\
\hline$\%$ Positive & $44.44 \%$ & $38.89 \%$ & $38.89 \%$ & $55.56 \%$ \\
\hline t-statistic & 0.92 & -1.34 & -1.52 & -0.60 \\
\hline \multicolumn{5}{|l|}{ Mexico (in Dollars) } \\
\hline Mean CAR & $-0.82 \%$ & $-1.99 \%$ & $-2.37 \%$ & $-2.60 \%$ \\
\hline$\%$ Positive & $22.22 \%$ & $22.22 \%$ & $33.33 \%$ & $22.22 \%$ \\
\hline t-statistic & $-2.93^{* * *}$ & $-2.94^{* * *}$ & $-2.19^{* *}$ & $-2.20^{* *}$ \\
\hline
\end{tabular}

*Statistically significant at the .10 level; **Statistically significant at the .05 level; ***Statistically significant at the .01 level

The results are shown in Table 4. We find a significant impact on the Mexican stock market of such violent events, but this impact does not carry over to other markets. Although the Emerging Markets and Latin America indexes are negative for all the event windows studied, they are not statistically significant. Further less than $50 \%$ of the events experienced positive abnormal returns during the event windows. The results presented here suggest that while violence in Mexico has a detrimental impact on the stock market in the country, which suggests investors are updating their expectations about firm value in Mexico, it has had no effect on other emerging markets or the U.S. market. Therefore, we find that the effect of violence in Mexico on the stock market is local, supporting $\mathrm{H} 2$.

\section{CONCLUSIONS}

In this paper, we study the stock price reactions to violent events in Mexico. We identify 18 violent events that had international news exposure and conduct an event study to gauge if these events had any impact on the stock market. Prior literature has focused on the markets' reaction to terrorism attacks. Our paper is important as we show that the markets respond to news of violent events even in a country that has no perceived terrorism. Further, we contribute to the literature studying the effects of the increased violence in Mexico by showing the impact on the Mexican financial market of such events. We find that overall, the Mexican stock market reacts negatively to the news of violence. We find no effect of the violence news on an index of Latin American, other emerging, or the U.S. stock markets. We conclude that violent events are bad news to investors, and this effect is local, as it does not spillover to other markets.

To fully understand the consequences of violent events in Mexico on the financial markets, further research should focus on other financial markets, such as bonds, exchange rates, etc., as well as a focus on understanding the differential impacts among industries and firms. At the same time, more single country studies are needed to fully understand how firms and investors suffer the consequences of terrorist attacks and increased violence, and whether there are spillover effects of increased violence on other markets.

\section{AUTHOR BIOGRAPHIES}

Magali Valero is an associate professor of finance at the University of Michigan, Dearborn. Her research topics include international cross-listings, poverty, economic development, and the financial market and economy of Mexico. Department of Accounting and Finance. University of Michigan Dearborn. 19000 Hubbard Drive, Dearborn, MI, 48126. Phone: (313) 583-6532. mvalero@umich.edu

Jorge Valero is a professor of economics at Universidad Autónoma de Nuevo León. His research topics include problems of economic development of Mexico, including formal and empirical analysis in informality, remittances, education, poverty, nutrition, crime, and the financial market in Mexico. Facultad de Economía. Avenida Lázaro 
Cárdenas 4600 Ote. Fracc. Residencial Las Torres. Monterrey, Nuevo León, C.P. 64930, Mexico. Phone: (52) 8183294000 Ext. 2443.jnvalero@gmail.com

\section{REFERENCES}

Abadie, A., \& Gardeazabal, J. (2003). The economic cost of conflict: a case study of the Basque country. American Economic Review, 93, 113-132.

Aslam, F., \& Kang, H. (2015). How different terrorist attacks affect the stock markets. Defence and Peace Economics, 26(6), 634-648.

Apergis, E., \& Apergis, N. (2016). The 11/13 Paris terrorist attacks and stock prices: The case of the international defense industry. Finance Research Letters, 17, 186-192.

Balmori de la Miyar, J.R. (2016). The economic consequences of the Mexican drug war. Peace Economics, Peace Science Public Policy, 22(3), 213-246.

Bel, G., \& Holst, M. (2018). Assessing the effects of the Mexican drug war on economic growth: An empirical analysis. Southern Economic Journal, 85(1), 276-303.

Brounrn, D., \& Derwall, J. (2010). The impact of terrorist attacks on international stock markets. European Financial Management, 16(4), 585-598.

Brown, R., \& Velasquez, A. (2017). The effect of violent crime on the human capital accumulation of young adults. Journal of Development Economics, 127, 1-12.

Brown, S.J., \& Warner, J.B. (1985). Using daily stock returns; the case of event studies. Journal of Financial Economics, 14, 331.

Chen, A.H., \& Siems, T.F. (2004). The effects of terrorism on global capital markets. European Journal of Political Economy, 20, 349-366.

Chesney, M., Reshetar, G. \& Karaman, M. (2011). The impact of terrorism on financial markets: an empirical study. Journal of Banking and Finance, 35, 253-267.

Dai, Y., Rau, P.R., Stouraitis, A., \& Tan, W. (2020). An ill wind? Terrorist attacks and CEO compensation. Journal of Financial Economics, 135, 379-398.

Eckstein, Z., \& Tsiddon, D. (2004). Macroeconomic consequences of terror: theory and the case of Israel. Journal of Monetary Economics, 51, 971-1002.

Enamorado, T., Lopez-Calva, L., \& Rodriguez-Castelan, C. (2014). Crime and growth convergence: evidence from Mexico. Economics Letters, 125 (1), 9-13.

Enamorado, T., Lopez-Calva, L.F., Rodriguez-Castelan, C. \& Winkler, H. (2016). Income inequality and violent crime: Evidence from Mexico's drug war. Journal of Development Economics, 120, 128-143.

Fama, E.F., L. Fisher, Jensen, M.C., \& Roll, R. (1969). The adjustment of stock prices to new information. International Economic Review, 10, 1-21.

Freytag, A., Kruger, J.J., Meierrieks, D., \& Schneider, F. (2011). The origins of terrorism: Cross-country estimates of socioeconomic determinants of terrorism. European Journal of Political Economy, 27, 55-516.

Goel, S., Cagle, S., \& Shawky, H. (2017). How vulnerable are international financial markets to terrorism? An empirical study based on terrorist incidents worldwide. Journal of Financial Stability, 33, 120-132.

Karolyi, A. (2006). What do we know about terrorism and the financial markets? Canadian Investment Review, Summer 2006.

Karolyi, A., \& Martell, R. (2010). Terrorism and the stock market. International Review of Applied Financial Issues and Economics, 22, 285-314.

Kollias, C., Papadamou, S., \& Stagiannis, A. (2011). Terrorism and capital markets: The effects of the Madrid and London bomb attacks. International Review of Economics and Finance, 20, 532-541.

Llussá, F., \& Tavares, J. (2011). Which terror at which cost? On the economic consequences of terrorist attacks. Economic Letters, 110, 52-55.

Nasir, M., Rockmore, M., \& Tan, C.M. (2020). Do the lessons from micro-conflict literature transfer to high crime areas? Examining Mexico's war on drugs. The Journal of Development Studies, 56(1), 26-44.

Robles, G., Calderón, G., \& Magaloni, B. (2013). The economic consequences of violence and crime in Mexico. Poverty and Governance Series Working Paper, Stanford University.

Tingbani, I., Okafor, G., Tauringana, V., \& Zalata, M. (2019). Terrorism and country-level global business failure. Journal of Business Research, 98, 430-440.

Velazquez, A. (2020). The economic burden of crime: Evidence from Mexico. Forthcoming in The Journal of Human Resources.

Wang, A.Y., \& Young, M. (2020). Terrorist attacks and investor risk preference: Evidence from mutual fund flows. Forthcoming in Journal of Financial Economics. 